\title{
Article \\ Property Analysis of Slag Composite Concrete Using a Kinetic-Thermodynamic Hydration Model
}

\author{
Ki-Bong Park ${ }^{1}$, Yi-Sheng Wang ${ }^{2}$ and Xiao-Yong Wang ${ }^{1,2, *(\mathbb{D})}$ \\ 1 Department of Architectural Engineering, Kangwon National University, Chuncheon-si 24341, Korea; \\ kbpark@kangwon.ac.kr \\ 2 Department of Integrated Energy and Infra System, Kangwon National University, \\ Chuncheon-si 24341, Korea; wangyisheng@kangwon.ac.kr \\ * Correspondence: wxbrave@kangwon.ac.kr
}

check for updates

Citation: Park, K.-B.; Wang, Y.-S.; Wang, X.-Y. Property Analysis of Slag Composite Concrete Using a Kinetic-Thermodynamic Hydration Model. Appl. Sci. 2021, 11, 7191 https://doi.org/10.3390/app11167191

Academic Editor: Panagiotis

G. Asteris

Received: 12 July 2021

Accepted: 2 August 2021

Published: 4 August 2021

Publisher's Note: MDPI stays neutral with regard to jurisdictional claims in published maps and institutional affiliations.

Copyright: (c) 2021 by the authors. Licensee MDPI, Basel, Switzerland. This article is an open access article distributed under the terms and conditions of the Creative Commons Attribution (CC BY) license (https:// creativecommons.org/licenses/by/ $4.0 /)$.

\begin{abstract}
Slag is increasingly unitized for the production of sustainable concrete. This paper presents a procedure with which to analyze the property development of slag composite concrete. Experimental studies of the hydration heat and compressive strength development and simulation studies using a kinetic hydration model and a thermodynamic model were performed. First, we performed an experimental study of the isothermal hydration heat of cement-slag blends. Based on the results of the experimental study on cumulative hydration heat, the reaction degree of slag was determined. We found that the reaction degree of slag decreased as the slag content increased. Second, the reaction degree of slag and cement were used as the input parameters for the Gibbs energy minimization (GEM) thermodynamic equilibrium model. Moreover, the phase assemblage of hydrating cement-slag was determined. The trends of calcium silicate hydrate $(\mathrm{CSH})$ are similar to those of strength. Based on the $\mathrm{CSH}$ content, the strength of hardening cement-slag blends was determined. In addition, the calcium hydroxide $(\mathrm{CH})$ content resulting from the thermodynamic model shows good agreement with the experimental results. In summary, the integrated kinetic-thermodynamic model is useful for analyzing the properties of cement-slag blends.
\end{abstract}

Keywords: slag; hydration; kinetic model; thermodynamic equilibrium model; heat; strength

\section{Introduction}

Granulated blast furnace slag is a by-product of steel and iron manufacture and can be used as a mineral admixture for producing sustainable concrete. Slag composite concrete shows various advantages, such as good workability, high late-stage strength, good resistance to chloride penetration, and good appearance [1,2]. In addition, slag composite concrete is a sustainable alternative because it has lower $\mathrm{CO}_{2}$ emissions and the cost of materials is lower than plain concrete [2-4].

Numerous experimental and theoretical studies have been carried out to investigate the reaction degree, hydration heat, and strength of slag composite concrete.

First, regarding experimental studies, Erdogan and Koçak [5] found that the compressive strength of slag composite concrete has a strong linear relationship with hydration heat at the same age. Lumley et al. [6] and Iyoda et al. [7] found that as the replacement percentage increases and the water/binder ratio decreases, the reaction degree of slag decreases. Liu et al. [8] found that slag cement has a positive effect on late-stage strength and workability and a negative effect on the capillary absorption and salt scaling of ultrahigh-performance concrete. Castellano et al. [9] found that $40 \%$ slag composite concrete showed a strength crossover, while $80 \%$ slag composite concrete did not show a strength crossover. Kim et al. [10] found that $30 \%$ is the optimal replacement percentage of slag for producing high early-strength concrete.

Second, regarding theoretical modeling, Bougara et al. [11] evaluated the compressive strength of slag composite concrete using a statistical model of the slag replacement ratio, 
curing temperature, water/binder ratio, and bound water content. Kandiri et al. [12] evaluated the compressive strength of slag composite concrete using artificial neural networks. Wan et al. [13] performed a second-degree regression of the 3, 7, 14, and 28-day strength of cement-slag-fly ash ternary composite. Tan et al. [14] proposed a kinetic hydration model to determine the hydrating layer thickness of slag particles. Xie et al. [15] developed a kinetic hydration model for slag geopolymer and found that the slag reaction consists of a process of phase boundary reaction and a process of diffusion. Fernández et al. [16] constructed a thermodynamic model of cement-slag blends and evaluated the hydration product assemblage. Schöler et al. [17] analyzed the hydration products of cement-slag-fly ash-limestone quaternary blends and found the optimal combination for strength. Han et al. [18] analyzed the hydration kinetics of cement-slag composite considering the influence of the slag replacement percentage and curing temperature. Gruyaert et al. [19] analyzed the reaction extent of cement, slag, and total binder in binary blends based on the experimental study results of hydration heat, combined water, and backscattered electron image analysis.

Based on our investigations, we found that previous models in this field have several weak points. First, the models of Bougara et al. [11], Kandiri et al. [12], and Wan et al. [13] are statistical models that are difficult to generalize to different mixing proportions and various curing conditions. Second, the models of Tan et al. [14] and Xie et al. [15] are used for alkali-activated slag concrete. It is difficult to simulate the hydration of cement-slag binary composite concrete in these models. Third, the models of Fernández et al. [16] and Schöler et al. [17] are useful for evaluating the phase assemblages of hydration products, however, the reaction degrees of slag in the works of Fernández et al. [16] and Schöler et al. [17] were derived from experimental measurements, which require a large amount of time and money. In other words, if a kinetic model could be used to calculate the reaction extent of slag in binary blends of cement-slag, the use of time- and cost-consuming experimental measurements can be eliminated. Fourth, the studies of Han et al. [18] and Gruyaert et al. [19] do not analyze the interactions between individual reactions of cement and slag. The coefficients of the kinetic models in the studies of Han et al. [18] and Gruyaert et al. [19] change as the mixtures change.

To overcome the weaknesses of previous models, this paper details a procedure to analyze the property development of slag composite concrete. We performed experimental and simulation studies on the hydration heat and strength of cement-slag blends. Based on the results of the experimental study of the hydration heat of binary blends of cement-slag, the reaction degree of slag was determined. The coefficients of the hydration model were constant for various mixtures. Moreover, the reaction extent of slag and cement were used as the input parameters of a Gibbs energy minimization (GEM) thermodynamic equilibrium model and the contents of $\mathrm{CSH}$ were determined. The strength of hardening cement-slag blends was determined using a linear equation of the CSH contents.

The structure of this paper is as follows: Section 1 presents the introduction; Sections 2 and 3 show a hydration-based property evaluation model and the experimental verification of the proposed model, respectively; Section 4 presents a discussion; and Section 5 contains the conclusion.

\section{Hydration-Based Property Evaluation Model of Binary Blends of Cement-Slag \\ 2.1. Cement Hydration Model}

Our previous studies $[20,21]$ utilized a kinetic model that mimics the hydration process for Portland cement. The material composition, such as the cement composition and the concrete mixtures, and the curing conditions, such as the curing temperature, are considered in this kinetic model. The model considers the kinetic process of cement hydration as a period of initial dormancy, a process of phase-boundary reaction, and a process of diffusion. The degree of hydration of the clinker composition $\alpha_{i}(i=1,2$, 3 , and 4 denote the mineral composition of cement, such as $\mathrm{C}_{3} \mathrm{~S}, \mathrm{C}_{2} \mathrm{~S}, \mathrm{C}_{3} \mathrm{~A}$, and $\mathrm{C}_{4} \mathrm{AF}$, respectively) can be calculated based on the numerical integration method in the time 
domain as $\alpha_{i}=\int_{0}^{t}\left(\frac{d \alpha_{i}}{d t}\right) d t$, where $\frac{d \alpha_{i}}{d t}$ is the rate of cement hydration. The equation for the rate of cement hydration $\frac{d \alpha_{i}}{d t}$ is simplified as follows:

$$
\begin{gathered}
\frac{d \alpha_{i}}{d t}=f\left(B, C, D e, k r_{i}\right) * \lambda_{1} * \lambda_{2}, \\
\alpha=\frac{\sum_{i=1}^{i=4} \alpha_{i} m_{i}}{\sum_{i=1}^{i=4} m_{i}},
\end{gathered}
$$

where $B$ and $C$ denote the rate-determining coefficients in the period of initial dormancy, $D e$ and $k r_{i}$ are the reaction parameters in diffusion-controlled periods and phase boundarycontrolled periods, respectively, and $\lambda_{1}$ and $\lambda_{2}$ consider the capillary water withdrawal during the hydration process. The withdrawal of capillary water can lower the rate of hydration. $\lambda_{1}$ covers the capillary water withdrawal because of the development of microstructure, while $\lambda_{2}$ covers the capillary water withdrawal because of the consumption of capillary water $\left(\lambda_{2}=\frac{W_{c a p}}{W_{0}}\right.$, where $W_{\text {cap }}$ and $W_{0}$ are the mass of capillary water and the mass of mixed water in concrete mixtures, respectively). For $m_{i}, i=1,2,3$, and 4 denote the mass fractions of the mineral composition of cement, such as $\mathrm{C}_{3} \mathrm{~S}, \mathrm{C}_{2} \mathrm{~S}, \mathrm{C}_{3} \mathrm{~A}$, and $\mathrm{C}_{4} \mathrm{AF}$, respectively. $\alpha$ is the reaction degree of Portland cement. For concrete with a normal strength, the withdrawal of capillary water is less obvious, while for high-strength concrete at the late age of hydration, the withdrawal of capillary water is significant. Due to the consideration of capillary water withdrawal, the kinetic model is valid for both concrete with normal strength and concrete with high strength. The degree of hydration of Portland cement can be determined based on the individual hydration degree of the clinker component.

\subsection{Reaction Model of Slag in Cement-Slag Composite}

Slag can be used as a mineral admixture to replace partial cement. Based on the experimental results for the isothermal hydration heat of binary blends of cement-slag, Maekawa et al. [22] found that the reaction of slag has a similar kinetic process to that of cement. On the other hand, slag is a cementitious material that has both hydraulicity and pozzolanicity [23]. The reaction of slag can be activated by calcium hydroxide $(\mathrm{CH})$. In hydrating cement-slag blends, $\mathrm{CH}$ is produced by the hydration of cement and $\mathrm{CH}$ is consumed by the reaction of slag. Considering the kinetic process of the slag reaction and the cementitious material property of slag, the reaction equation for slag in binary blends can be written as $\alpha_{S G}=\int_{0}^{t}\left(\frac{d \alpha_{S G}}{d t}\right) d t$, where $\alpha_{S G}$ is the extent of the reaction of slag. The differential equation of the reaction rate of slag in the binary blends is shown as follows:

$$
\begin{aligned}
& \frac{d \alpha_{S G}}{d t}=\frac{C H(t)}{P} * \lambda_{2} * f_{S G}\left(B_{S G}, C_{S G}, D e_{S G 0}, k r_{S G}\right) \\
& =\frac{C H(t)}{P} * \lambda_{2} * \frac{3 \rho_{w}}{v_{S G} r_{S G 0} \rho_{S G}} \frac{1}{\frac{B_{S G}}{\left(\alpha_{S G}\right)^{1.5}+C_{S G} *\left(\alpha_{S G}\right)^{3}}-\frac{r_{S G 0}}{D_{e S G 0} * \ln \left(\frac{1}{\alpha_{S G}}\right)}+\frac{r_{S G 0}}{D_{e S G 0} * \ln \left(\frac{1}{\alpha_{S G}}\right)}\left(1-\alpha_{S G}\right)^{\frac{-1}{3}}+\frac{1}{k_{r S G}}\left(1-\alpha_{S G}\right)^{\frac{-2}{3}}}
\end{aligned}
$$

where $\alpha_{S G}$ is the extent of the reaction of slag; $\frac{d \alpha_{S G}}{d t}$ is the rate of the reaction of slag; $B_{S G}$ and $C_{S G}$ are the reaction parameters of slag in a period of dormancy; $D e_{S G 0}$ is the initial value of the reaction parameter of slag in a diffusion-controlled period; $k r_{S G}$ is the reaction parameter of slag in a period of phase boundary control; $\rho_{w}$ and $\rho_{S G}$ are the mean densities of water and slag, respectively; $v_{S G}$ is the mass of consumed $\mathrm{CH}$ when one gram of slag reacts $\left(v_{S G}=0.25-0.1 \frac{P}{P+C_{0}}\right.$, where $C_{0}$ and $P$ denote the mass of cement and slag in the concrete mixtures, respectively); $r_{S G 0}$ is the particle radius of slag; and $\mathrm{CH}(t)$ is the mass of $\mathrm{CH}$ in the hydrating blends. 
In Equation (3), the item $\frac{C H(t)}{P}$ considers the dependence of the reaction of slag on the available $\mathrm{CH}$ content in hydrating cement-slag blends. The item $\lambda_{2}\left(\lambda_{2}=\frac{W_{\text {cap }}}{W_{0}}\right)$ considers the dependence of the slag reaction on the available capillary water content in hydrating blends of cement-slag. In summary, Equation (3) considers the hydraulicity of slag using item $\lambda_{2}$ and considers the pozzolanicity of slag using item $\frac{C H(t)}{P}$. In addition, the item $D_{e S G O} * \ln \left(\frac{1}{\alpha_{S G}}\right)$ considers the densification of hydration products and the decrease in the accessibility of reactants during the diffusion control process [24].

\subsection{Interactions between Individual Reactions of Cement and Slag}

For a binary composite of cement-slag, individual reactions of cement and slag coexist and show interactions. This study uses the capillary water content and $\mathrm{CH}$ content in the hydrating system to consider the interactions between the individual reactions of cement and slag. The content of capillary water in the hydrating composite system can be determined as follows:

$$
W_{\text {cap }}=W_{0}-0.4 * C_{0} * \alpha-0.45 * \alpha_{S G} * P,
$$

where $0.4 * C_{0} * \alpha$ and $0.45 * \alpha_{S G} * P$ are the mass of consumed capillary water from the hydration of cement and the reaction of slag, respectively.

For hydrating a cement-slag binary composite, the mass of $\mathrm{CH}$ can be calculated as follows:

$$
C H(t)=C_{C E} * C_{0} * \alpha-v_{S G} * \alpha_{S G} * P,
$$

where $\mathrm{CH}_{C E}$ means the mass of $\mathrm{CH}$ produced for $1 \mathrm{~g}$ of hydrated cement. $\mathrm{CH}_{C E} * \mathrm{C}_{0} * \alpha$ is the mass of $\mathrm{CH}$ produced by the hydration of cement. $v_{S G} * \alpha_{S G} * P$ is the mass of $\mathrm{CH}$ consumed by the reaction of slag.

\subsection{Hydration Heat}

For hydrating a binary composite system, the slag reaction and cement hydration contribute to the hydration heat. The total released heat equals the sum of the individual reactions of binders as follows:

$$
Q=C_{0} * H_{C} * \alpha+P * H_{S G} * \alpha_{S G},
$$

where $H_{C}$ and $H_{S G}$ denote the specific heat generation from cement hydration and the slag reaction, respectively. $H_{C}$ can be determined based on the cement's mineral composition [22]. The value of the specific heat generation of slag reaction $H_{S G}$ was proposed as $630 \mathrm{~J} / \mathrm{g}[25,26]$. The terms $C_{0} * H_{C} * \alpha$ and $P * H_{S G} * \alpha_{S G}$ consider the release of heat from the cement hydration and the slag reaction, respectively.

As shown in Equation (6), cumulative hydration heat can be used as an indirect method to determine the extent of the reaction of slag. Moreover, the coefficients of the reaction model of slag can be determined based on the calibration of the results of the experimental study of hydration heat. In addition, because the proposed model covers the interactions between individual reactions of slag and cement, the coefficients of the slag reaction model and the cement hydration model are constants for various mixtures with different slag replacement percentages and water/binder ratios.

\subsection{Summary of the Proposed Model}

The Gibbs energy minimization program (GEM-Selektor) is widely used for analyzing the phase assemblage, pore solution composition, and durability of cement-based materials $[16,17,27]$. The strength development of hydrating binary cement-slag closely relates to the phase assemblage of the hydration products $[16,17,27]$.

This paper proposes an integrated kinetic-thermodynamic model of binary blends of cement-slag. As shown in Figure 1, the reaction extent of slag can be determined based on the results of the experimental study of the hydration heat of binary blends of cement-slag. 
Moreover, the reaction extent of slag and cement are used as the input parameters of a Gibbs energy minimization (GEM) thermodynamic equilibrium model. The contents of the hydration products are determined. Moreover, strength development is evaluated using the contents of the products of hydration.

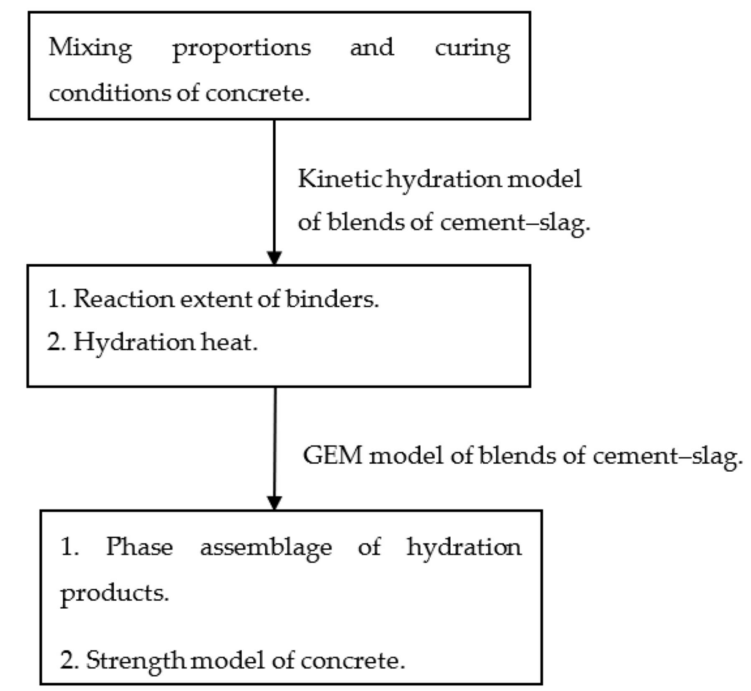

Figure 1. The simulation framework of cement-slag concrete.

\section{Experimental Studies and Modeling}

\subsection{Materials and Methods}

Portland cement (type I) and blast furnace slag were used to prepare the paste specimen. Table 1 shows the chemical composition of cement and slag. The $\mathrm{SiO}_{2}$ content in slag is much higher than that in cement, which favors the production of secondary calcium silicate hydrate and contributes to the strength development. Table 2 shows the physical properties of cement and slag. Table 3 shows the specimens and test stages. The water/binder ratio of the specimens was 0.5 . The slag replacement percentages were $0 \%$, $30 \%$, and $50 \%$.

Table 1. Chemical composition of cement and slag.

\begin{tabular}{ccccccccccc}
\hline & $\mathrm{CaO}$ & $\mathrm{SiO}_{2}$ & $\mathrm{Al}_{2} \mathrm{O}_{3}$ & $\mathrm{Fe}_{2} \mathrm{O}_{3}$ & $\mathrm{MgO}$ & $\mathrm{SO}_{3}$ & $\mathrm{Na}_{2} \mathrm{O}$ & $\mathrm{TiO}_{2}$ & Loss on Ignition \\
\hline Cement & 64.7 & 21.1 & 5.77 & 3.14 & 0.89 & 1.61 & 0.25 & 0.22 & 2.32 \\
\hline Slag & 34.63 & 35.85 & 9.79 & 0.46 & 13.84 & 3.45 & 0.35 & 0.62 & 1.01 \\
\hline
\end{tabular}

Table 2. Physical properties of the binder components.

\begin{tabular}{ccc}
\hline & Fineness $\left(\mathrm{cm}^{2} / \mathbf{g}\right)$ & Specific Gravity \\
\hline Cement & 3300 & 3.15 \\
Slag & 4500 & 2.90 \\
\hline
\end{tabular}

Table 3. Specimens and tests.

\begin{tabular}{cccc}
\hline Slag Replacement Percentages & Water/Binder Ratio & Curing Temperature & Isothermal Calorimetry Tests \\
\hline 0 & 0.5 & $20{ }^{\circ} \mathrm{C}$ & From mixing time to 7 days \\
$30 \%$ & & $3,7,14,28$, and 90 days \\
\hline
\end{tabular}

The hydration heat and the compressive strength of the paste specimen were measured. The curing temperature of the specimens was $20^{\circ} \mathrm{C}$. The hydration heat was measured 
using isothermal calorimetry from the time of mixing to 7 days. The strengths were measured from the early stages (three days) to the late stage of 90 days. Cubic specimens $\left(50 * 50 * 50 \mathrm{~mm}^{3}\right)$ were used for strength testing. Sealed curing was used for the specimens in the compressive strength test.

\subsection{Experimental Results}

Figure 2a shows the experimental results of the rate of heat of hydration. The rate of hydration heat was normalized by the mass of the binder. First, for plain paste, the rate of hydration showed three peaks. The first peak occurred at the starting time, which was due to the rapid dissolution of $\mathrm{C}_{3} \mathrm{~A}$. The second peak occurred at about $12 \mathrm{~h}$, which was due to the hydration of $\mathrm{C}_{3} \mathrm{~S}$ of cement. The third peak occurred at about $17 \mathrm{~h}$, which was due to the renewed dissolution of the aluminum of cement. After 3 days, the rate of hydration heat was low because diffusion became the controlling process of hydration. Second, as the replacement percentage of slag increased from $0 \%$ to $30 \%$ and $50 \%$, the rate of hydration heat decreased. This was due to the dilution effect of slag addition. For specimens with $30 \%$ and $50 \%$ slag, the time corresponding to the second peak $\left(C_{3} S\right.$ peak) was similar to that of plain concrete. Meanwhile, the third peak was much higher and sharper than the second peak. This was due to the aluminum phase in slag being much higher than that in cement. Third, Figure $2 \mathrm{~b}$ shows the hydration heat normalized by the mass of cement. From mixing to the time of $9 \mathrm{~h}$, the three curves of plain, 30\% slag, and 50\% slag merged together. This means that the slag reaction did not start at an early stage. In other words, in the early stage, the slag reaction was in the dormant period. After this stage, the difference in hydration heat between the control specimen and the slag-blended specimen was the result of the slag reaction.



(a) Hydration heat normalized by the mass of binder.

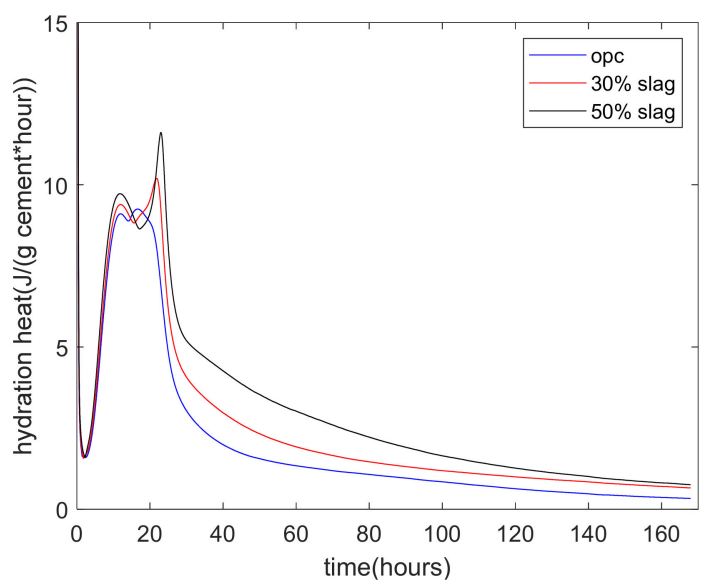

(b) Hydration heat normalized by the mass of cement.

Figure 2. Hydration heat of paste.

Figure 3 shows the strength development. At 3, 7, and 14 days, as the slag replacement percentage increased, the compressive strength of the concrete was reduced. This was due to the dilution effect of slag. Meanwhile, after curing for 28 days, the compressive strength of the slag composite specimen was higher than that of the plain specimen due to the reaction of the slag. In other words, strength crossover phenomena occurred between the slag-blended specimens and the plain specimens. 


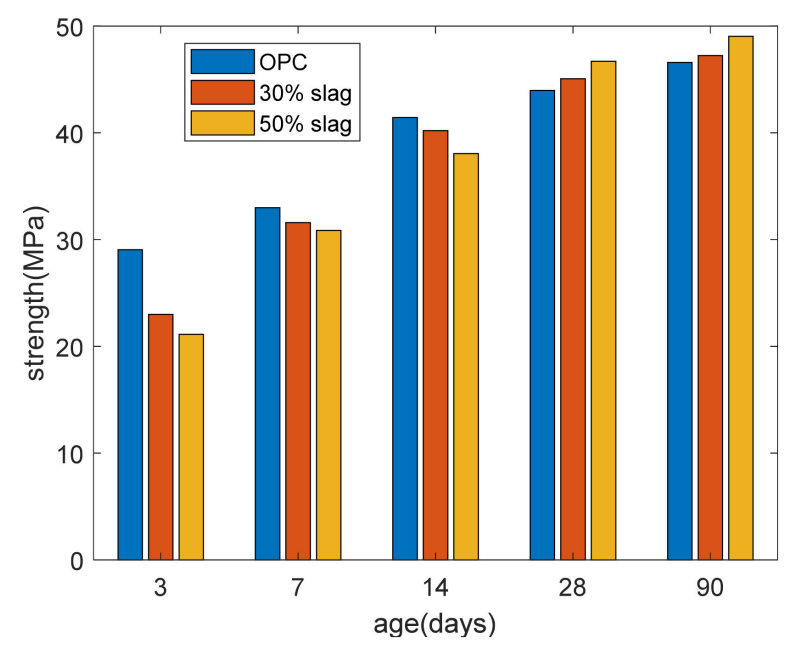

Figure 3. Strength of paste.

\subsection{Modeling}

\subsubsection{Kinetic Model}

Equation (6) shows that the hydration heat of blends of cement-slag is dependent on the individual reactions of cement and slag. The Portland cement hydration model can determine the heat release from cement hydration. Thus, using the experimental results for cumulative heat, the reaction coefficients of the reaction model of slag were determined and are shown in Table 4 . Figure 4 shows the results of the analysis of the heat of hydration. As a very early age (from mixing to about $5 \mathrm{~h}$ ), the increase in the cumulative hydration heat was slow because the hydration of the binder was in a period of initial dormancy. From $5 \mathrm{~h}$ to about $20 \mathrm{~h}$, the increase in the cumulative hydration heat became quicker because the phase boundary reaction was the controlling process of hydration. After $20 \mathrm{~h}$, the increase in the cumulative hydration heat became much slower because diffusion was the controlling process of hydration. Moreover, as the slag replacement percentage increased, the cumulative heat of the hydration decreased. This was because slag has a much slower reaction rate than cement.

Table 4. Reaction coefficients of the reaction model of slag.

\begin{tabular}{cccc}
\hline$B_{S G}(\mathrm{~cm} / \mathrm{h})$ & $C_{S G}(\mathrm{~cm} / \mathrm{h})$ & $k_{r S G}(\mathrm{~cm} / \mathrm{h})$ & $D_{e S G 0}\left(\mathrm{~cm}^{2} / \mathbf{h}\right)$ \\
\hline $8.93 \times 10^{-9}$ & 0.10 & $1.0 \times 10^{-5}$ & $1.86 \times 10^{-11}$ \\
\hline
\end{tabular}

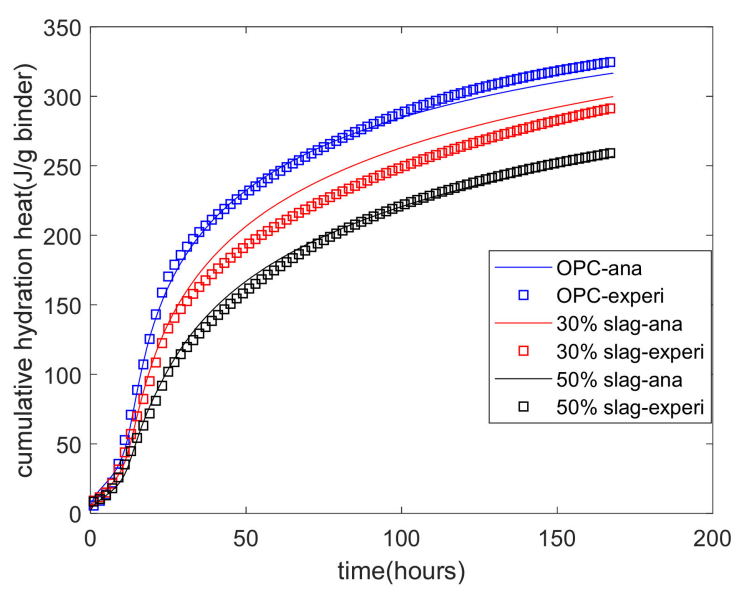

Figure 4. Analysis results for the cumulative hydration heat. 
Figure 5 shows a parameter study of cement-slag blends. Figure 5 a shows that as the slag replacement percentage increased, the hydration degree of cement increased. This was because of the increase in the capillary water concentration from the dilution effect of slag. Figure $5 \mathrm{~b}$ shows that as the slag replacement percentage increased, the reaction degree of slag decreased. This was due to the weakening of the alkali activation effect of $\mathrm{CH}$ for higher volumes of slag. Moreover, the slag reaction degree was much lower than the hydration degree of cement. Figure $5 c$,d shows the components of hydration heat-i.e., the total hydration heat, the heat from Portland cement hydration, and the heat from the slag chemical reaction. For a $50 \%$ slag composite paste at the age of 7 days, about $68 \%$ of the heat was from cement hydration. In other words, although the mass fraction of cement was the same as that of slag, the hydration heat from cement hydration was much higher than that from the slag reaction.



(a) Reaction extent of cement.

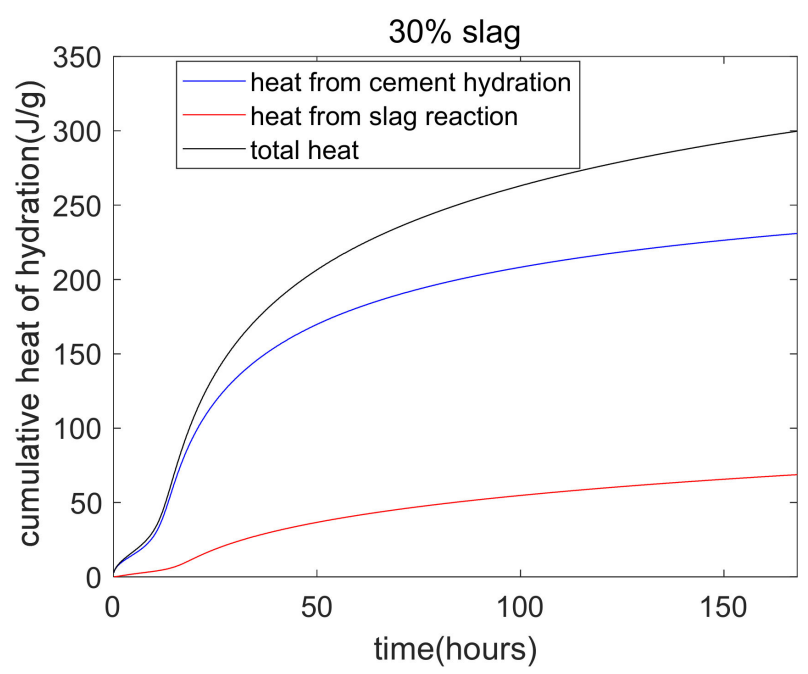

(c) Heat component of $30 \%$ slag paste.



(b) Reaction extent of slag.

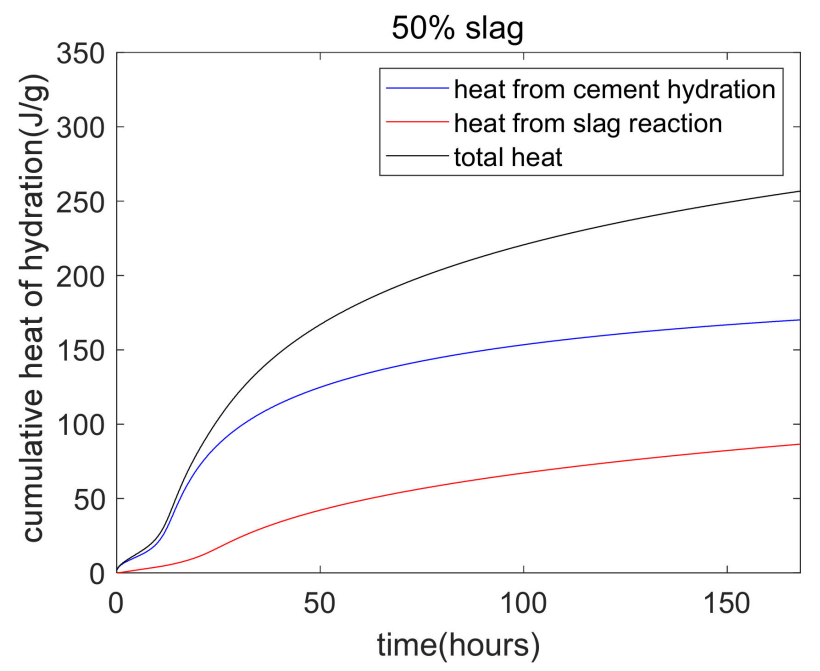

(d) Heat component of $50 \%$ slag paste.

Figure 5. Parameter analysis of the hydration model.

Figure $5 b$ shows the extent of the slag reaction at an early age (from the time of mixing to 7 days). The proposed model can evaluate the reaction degree of slag at various stages, such as at early and late stages. Iyoda et al. [7] measured the reaction extent of slag over a longer term using selective dissolution methods. The water/binder ratio of the 
specimen was 0.5 , and the slag replacement percentages were $42 \%$ and $67 \%$, respectively. The curing temperature was $20^{\circ} \mathrm{C}$. The reaction extent of slag was measured from 3 to 91 days. As shown in Figure 6a,b, the analysis of the reaction extent of slag over a longer term shows agreement with the results of this experiment. In other words, the proposed model is valid for various stages, such as early and late stages. Moreover, as the hydration model considers the interactions between the individual reactions of cement and slag, the coefficients of the reaction model do not change as the mixtures of the specimens change.



(a) Forty-two percent slag paste.

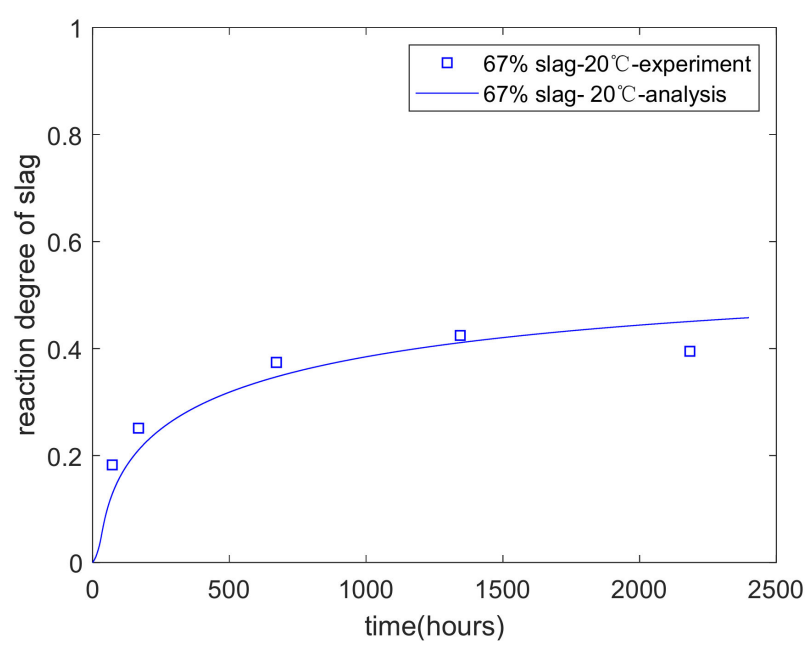

(b) Sixty-seven percent slag paste.

Figure 6. Long-term reaction degree of slag.

\subsubsection{Thermodynamic Equilibrium Model}

GEM-Selektor can be used to analyze the phase assemblage of hydrating products. When using GEM-Selektor, the compound composition of the cement and slag, curing temperatures, and reaction degree of the cement and slag are necessary input parameters. The phase assemblage is one of the output results of GEM-Selektor. GEM-Selektor, which incorporates the thermodynamic database of cement, is used to evaluate the equilibrium reaction of hydrating cement-slag blends $[16,17]$.

Figure $7 \mathrm{a}-\mathrm{c}$ shows the results of the phase assemblage from GEM-Selektor. First, for plain paste, as the hydration time increased, the contents of the compositions of clinkers deceased. In the early age, the consumption of $\mathrm{C}_{3} \mathrm{~S}$ was quick, while at the late age, the reaction rate of $\mathrm{C}_{3} \mathrm{~S}$ was slow because diffusion was the dominant process in late-stage hydration. In this study, CSHQ was assumed to be the major type of calcium silicate hydrate (CSH). The mass of CSH is much higher than that of other hydration products, such as $\mathrm{CH}$ and ettringite. In addition, the content of capillary water decreased as the hydration proceeded. At later stages, the content of capillary water reached a plateau and a decrease in capillary water was not obvious. Second, for 30\% and 50\% slag paste, at early stages, the consumption of slag was quick, while at late stages, the reaction rate of slag was slow because diffusion was the control process in the late-stage reactions. With the increase in the slag replacement ratios, the calcium hydroxide content decreased. This was due to the dilution effect and the chemical reaction of slag. With the increase in the slag replacement ratios, the content of hydrotalcite increased. This was because slag has a higher $\mathrm{MgO}$ content than cement, which favors the formation of hydrotalcite. At the late stages, 30\% slag paste had a higher CSH content than plain paste. This was because slag has a higher content of $\mathrm{SiO}_{2}$ than cement. 




(a) OPC paste.

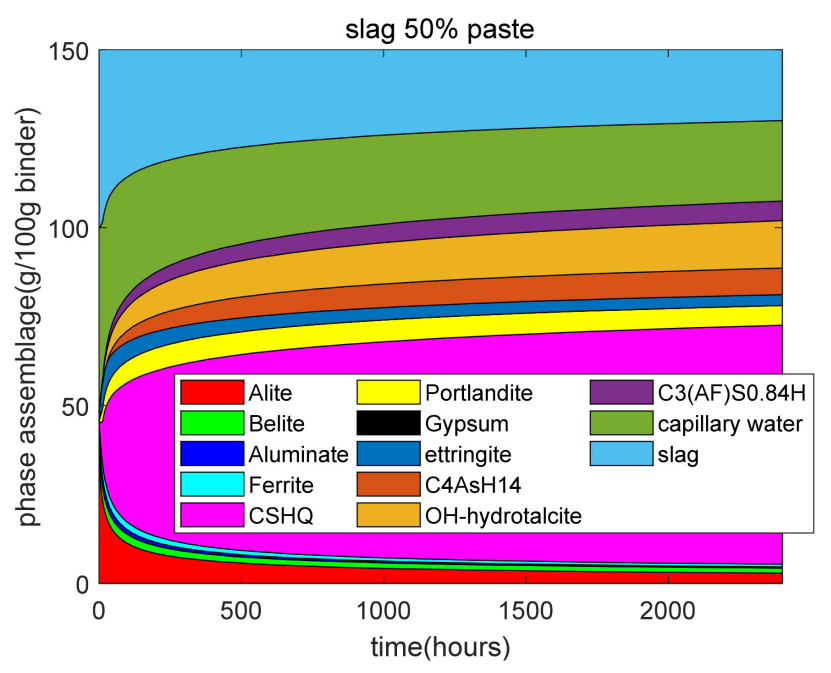



(b) Thirty percent slag paste.

(c) Fifty percent slag paste.

Figure 7. Phase assemblage of cement-slag blends.

Cho [28] measured the calcium hydroxide content of hydrating blends of cement-slag using thermogravimetric analysis. The water/binder ratio of the paste specimens was 0.5 ; the slag replacement percentages were $0 \%, 30 \%$, and $50 \%$; and the curing temperature of paste specimens was $20^{\circ} \mathrm{C}$. $\mathrm{CH}$ was measured from 3 days to 90 days. Figure 8 shows the analysis of GEM-Selektor, which is generally in agreement with Cho's experiments. For plain specimens, the $\mathrm{CH}$ content initially showed a rapid increase, exhibited a slow increase, then finally reached a plateau. For $50 \%$ slag paste, at the early stages, the $\mathrm{CH}$ content showed an increase because the hydration of cement was the dominant process, while in later stages, the $\mathrm{CH}$ content showed a decrease because the chemical reaction of slag became the dominant process. Compared with the plain specimen, the $50 \%$ slag specimen showed a much lower $\mathrm{CH}$ content. This was because of the consumption of $\mathrm{CH}$ from the slag reaction and the reduction in the cement content. 


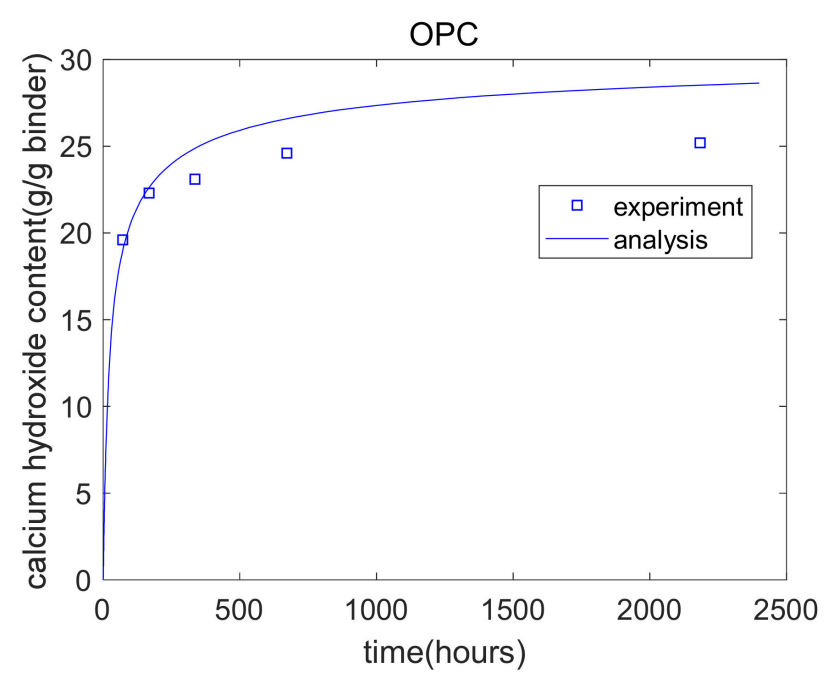

(a) OPC paste.

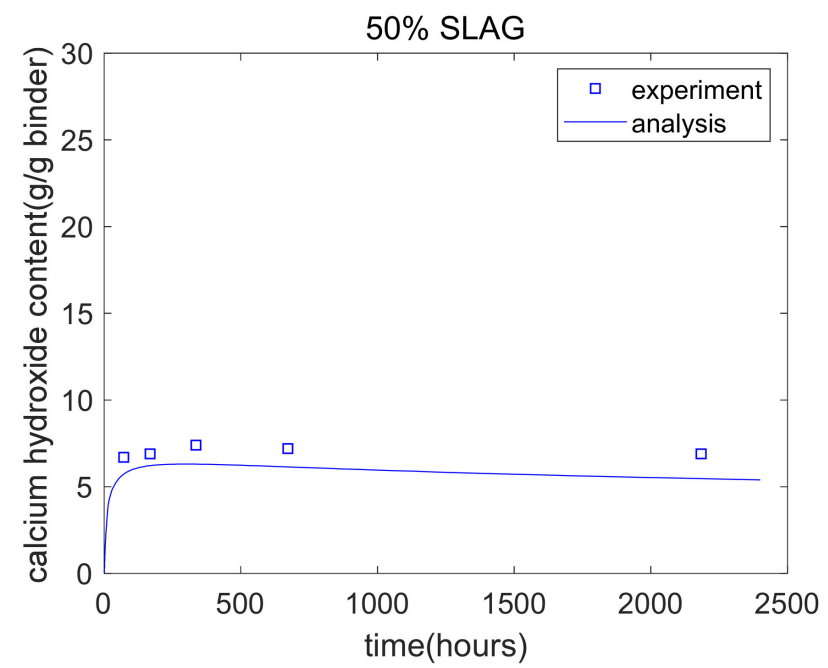

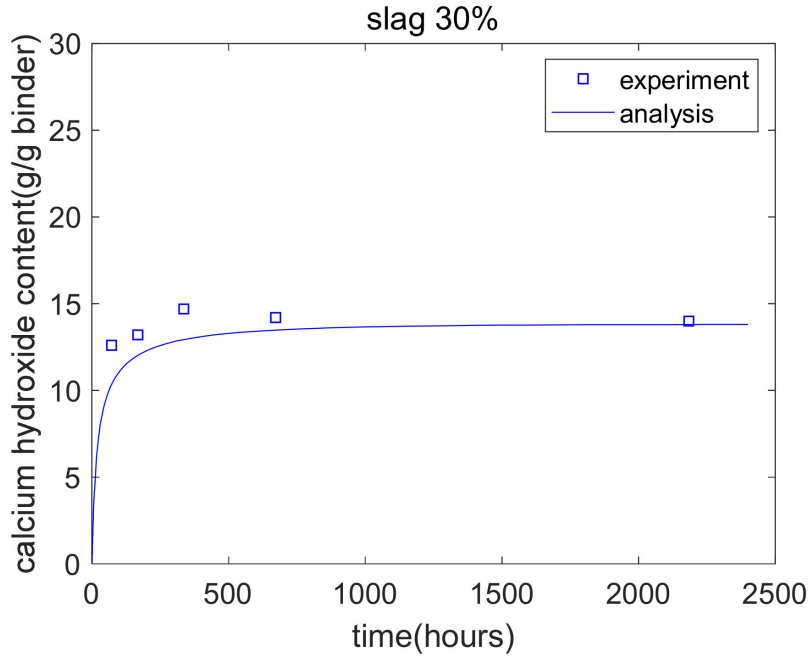

(b) Thirty percent slag paste.

(c) Fifty percent slag paste.

Figure 8. Calcium hydroxide analysis results.

Figure 9a shows the GEM-Selektor calculation results for combined water. For plain paste, at the early stages, the combined water content increased rapidly, while in later stages of curing, an increment in combined water was not obvious. Meanwhile, for blended paste in later stages of curing, the increment in combined water was more obvious than in plain paste. This was because of the reaction of slag in late stages. Moreover, with the increase in the slag replacement percentage, the content of combined water decreased. At later stages, $30 \%$ slag paste had a similar combined water content to that of plain paste, while $50 \%$ slag paste had a lower combined water content than that of plain paste. Figure $9 \mathrm{~b}$ shows that for specimens with different mixtures and different ages, the strength of concrete was linearly dependent on the combined water content. The combined water-based strength model is shown as follows:

$$
\text { Strength }=1.9473 * \text { combined } \quad \text { water }-10.22
$$




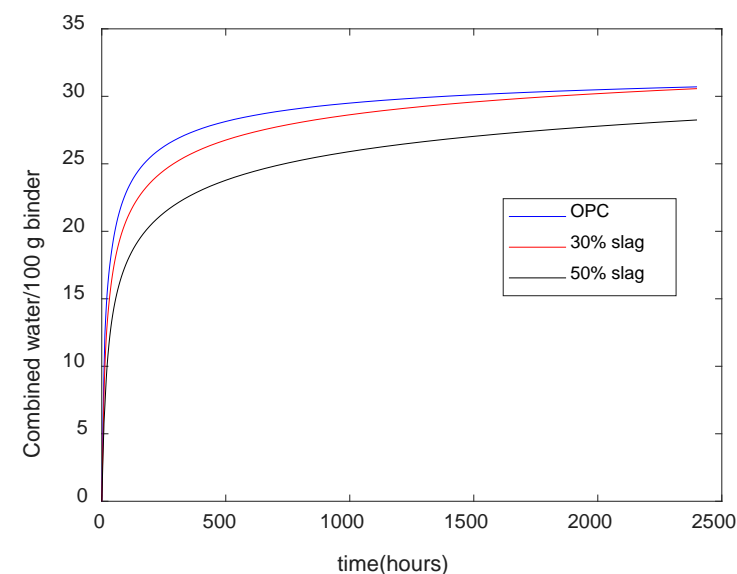

(a) Combined water content.

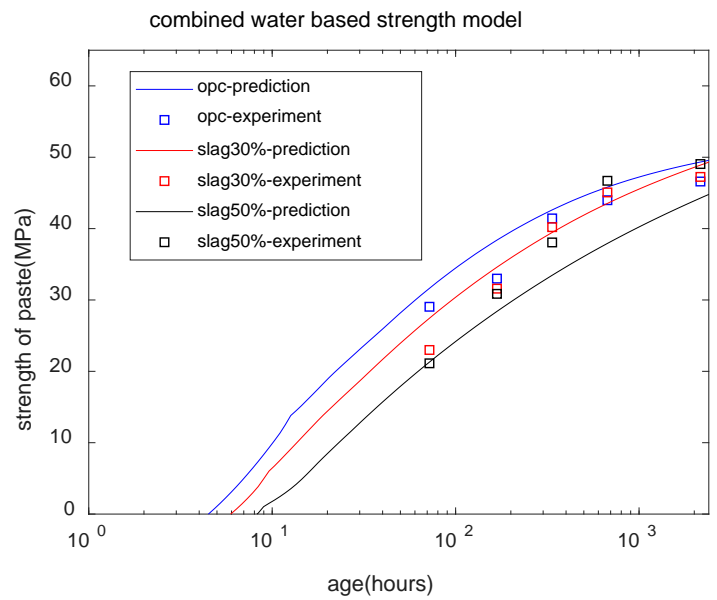

(c) Analysis results of the combined water-based strength model.

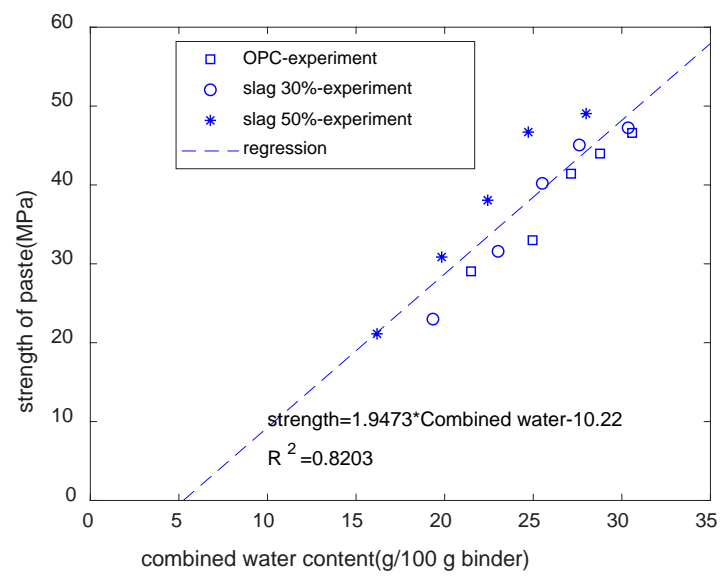

(b) Combined water content versus strength.

Figure 9. Combined water-based strength model.

Figure 9c shows that as the slag content increased, the starting time of the strength decreased. The trend of the starting time of the compressive strength showed a similarity to the final results. Slag composite concrete has a higher setting time than plain concrete. However, Figure $9 \mathrm{c}$ does not reflect the strength crossover phenomenon. The coefficient of determination of the combined water-based strength model is 0.82 .

Figure 10a shows the calculation results for CSH. In the early stages, slag-blended specimens had a lower CSH content, while at late stages, the composite specimens had a higher $\mathrm{CSH}$ content than the plain specimens. We can see that the trend in the CSH development is similar to that of compressive strength. Figure $10 \mathrm{~b}$ shows that for specimens with different mixtures and different ages, the strength of concrete was linearly dependent on the CSH content.

$$
\text { Strength }=0.9303 * \mathrm{CSH}-8.52
$$




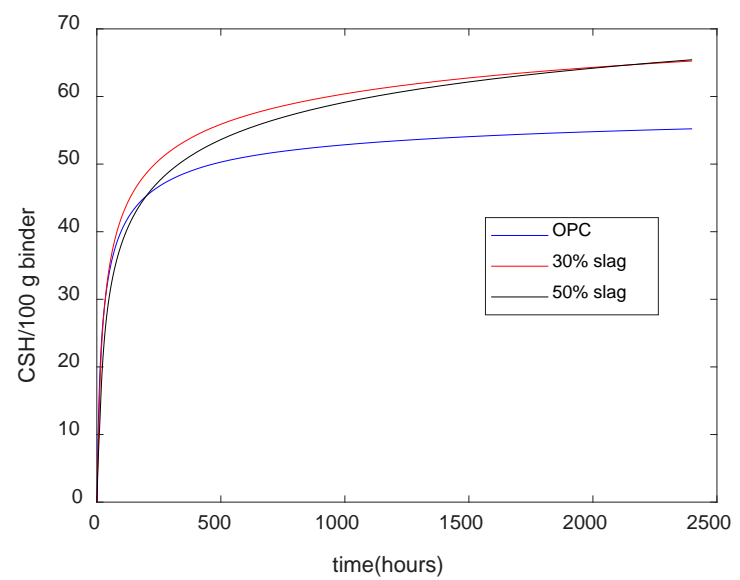

(a) $\mathrm{CSH}$ content.

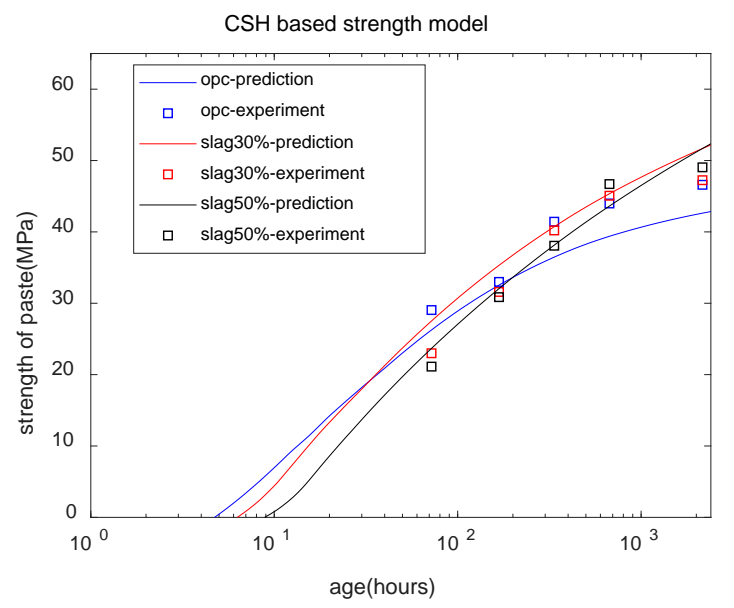



(b) $\mathrm{CSH}$ content versus strength.

Figure 10. CSH-based strength model.

Figure 10c shows that as the slag content increased, the starting time of the strength decreased. Figure 10c reflects the strength crossover phenomenon. As the slag content increased, the time of the strength crossover was extended. The coefficient of determination of the CSH-based strength model was 0.87-much higher than that of the combined waterbased strength model. Thus, compared with the combined water content, the CSH content was more suitable for the evaluation of the strength of cement-slag blends.

\section{Discussion}

Compared with previous studies, the main innovations of this paper are as follows:

First, using the results of the experimental study of the isothermal heat of hydration, we determined the reaction degree of slag. There are many experimental techniques for measuring the reaction extent of slag, such as the method of selective dissolution, the back-scattered electrons (BSE) image analysis method, and nuclear magnetic resonance testing [29-31]. These experimental methods are direct methods that directly demonstrate the reaction extent of slag. In contrast, isothermal hydration heat must be measured using the indirect method because the reactions of cement and slag are coupled together. The proposed model can separate the slag reaction from the hydration of Portland cement. Slag reactions are decoupled from the hydration of Portland cement. The contribution of slag to the hydration heat can be quantitatively determined. The results from using the indirect method in this study show agreement with the results of the direct method used in [7].

Second, the reaction degree of slag is an essential input parameter for GEM-Selektor. The proposed kinetic hydration model can determine the reaction degree of slag, which 
can be used as an input parameter for GEM-Selektor. The purpose of this study was not to replace GEM-Selektor but to provide convenient input parameters for GEM-Selektor. Moreover, because the coefficients of the proposed kinetic hydration model are constant for various mixtures, one set of experimental data on hydration heat is sufficient to determine the coefficients [32]. In other words, by using the proposed kinetic hydration model, the high time- and cost-consumption of other methods for the measurement of the reaction extent of slag can be eliminated.

Third, the theoretical implication of the work is that the proposed kinetic-thermo dynamic hydration model can predict the phase assemblage and strength development of cement-slag composite. Moreover, because concrete's durability properties are closely related to phase assemblage, the proposed model has potential application in predicting the durability properties of concrete. In addition, the main practical implication of the work is the material design and construction management of slag composite concrete. Based on the proposed model, concrete manufacturers can select the suitable slag replacement percentages, and the construction managers can confirm the stages of the removal of formwork from concrete structures.

\section{Conclusions}

This study demonstrates a procedure for analyzing the development of properties in slag composite concrete.

- $\quad$ First, we performed an experimental study on the isothermal hydration heat of blends of cement-slag. As the replacement percentages of slag increased from $0 \%$ to $30 \%$ and $50 \%$, the rate of hydration heat decreased. For specimens with $30 \%$ and $50 \%$ slag, the third peak for the dissolution of aluminum was much higher and sharper than the second peak. Moreover, using the experimental results for the isothermal heat of hydration, we determined the reaction extent of slag. The analysis found that, as the replacement percentage of slag increased, the reaction extent of the slag was reduced. In addition, because the proposed model covers the interactions between the individual reactions of slag and cement, the coefficients of the slag reaction model and the cement hydration model are constant for various mixtures.

- Second, during the isothermal calorimetry test, both cement hydration and slag reaction contribute to heat release. Because the proposed kinetic hydration model can separate the slag reaction from cement hydration, the contribution of the slag reaction on heat release can be determined. Moreover, the reaction degree of slag can be calculated. Thus, based on the use of the kinetic hydration model, the isothermal calorimetry test can be used as an indirect method for determining the reaction degree of slag.

- Third, the reaction extents of slag and cement were used as input parameters for the thermodynamic equilibrium model, and the phase assemblage of the hydration of cement-slag was determined. Using the experimental results for strength and the analysis results of GEM-Selektor, we found that the strength of paste is linearly dependent on the combined water content or CSH content. The coefficients of determination for the combined water-based strength model and the CSH-based strength model were 0.82 and 0.87 , respectively. The combined water-based strength model cannot reflect the strength crossover between plain paste and blended paste, while the CSH-based strength model can reflect the strength crossover. The CSH-based strength model showed that as the slag content increased, the time of the strength crossover grew longer. Compared with the combined water content, the CSH content is more suitable for the evaluation of the strength of cement-slag blends.

- Fourth, the specific contributions of this study are summarized as follows: (1) we proposed a kinetic hydration model to evaluate the reaction extent of slag and cement based on an isothermal calorimetry test, (2) we used the calculation results of the kinetic hydration model as input data for a thermodynamic model and evaluated the phase assemblage of hydrating cement-slag composite, and (3) we evaluated 
the strength development of hardening concrete using phase assemblage of composite concrete.

In summary, the evolution of the phase assemblage (chemical compositions) of cementslag blends can be calculated based on the integrated kinetic-thermodynamic model. Moreover, the development of the compressive strength (mechanical property) of composite concrete can be evaluated using a phase assemblage, such as CSH content or combined water content. Thus, the proposed model is useful for analyzing the chemical and mechanical properties of cement-slag blends.

Author Contributions: Conceptualization, K.-B.P.; methodology, Y.-S.W. and X.-Y.W.; vali-dation, K.-B.P., Y.-S.W. and X.-Y.W.; writing—original-draft preparation, K.-B.P. and X.-Y.W.; writing-review and editing, K.-B.P., Y.-S.W. and X.-Y.W.; visualization, Y.-S.W. and X.-Y.W.; supervision, K.-B.P. and X.-Y.W. All authors have read and agreed to the published version of the manuscript.

Funding: This study has been worked with the support of a research grant of Kangwon National University in 2017. This study is supported by the National Research Foundation of Korea (NRF2015R1A5A1037548, NRF-2020R1A2C4002093, NRF-2020R1A2C1102871). This study is supported by BK21 FOUR (Fostering Outstanding Universities for Research).

Institutional Review Board Statement: Not applicable.

Informed Consent Statement: Not applicable.

Data Availability Statement: The data presented in this study are available from the corresponding author upon reasonable request.

Conflicts of Interest: The authors declare no conflict of interest.

\section{References}

1. Amran, M.; Murali, G.; Khalid, N.H.A.; Fediuk, R.; Ozbakkaloglu, T.; Lee, Y.H.; Haruna, S.; Lee, Y.Y. Slag uses in making an ecofriendly and sustainable concrete: A review. Constr. Build. Mater. 2021, 272, 121942. [CrossRef]

2. Ren, G.; Yao, B.; Huang, H.; Gao, X. Influence of sisal fibers on the mechanical performance of ultra-high performance concretes. Constr. Build. Mater. 2021, 286, 122958. [CrossRef]

3. Bilal, H.; Chen, T.; Ren, M.; Gao, X.; Su, A. Influence of silica fume, metakaolin \& SBR latex on strength and durability performance of pervious concrete. Constr. Build. Mater. 2021, 275, 122124. [CrossRef]

4. Ren, M.; Wen, X.; Gao, X.; Liu, Y. Thermal and mechanical properties of ultra-high performance concrete incorporated with microencapsulated phase change material. Constr. Build. Mater. 2021, 273, 121714. [CrossRef]

5. Erdoğan, S.T.; Koçak, T.Ç. Influence of slag fineness on the strength and heat evolution of multiple-clinker blended cements. Constr. Build. Mater. 2017, 155, 800-810. [CrossRef]

6. Lumley, J.S.; Gollop, R.S.; Moir, G.K.; Taylor, H.F.W. Degrees of reaction of the slag in some blends with portland cements. Cem. Concr. Res. 1996, 26, 139-151. [CrossRef]

7. Iyoda, T.; Inokuchi, K.; Uomoto, T. Effect on slag hydration of blast-furnace slag cement in different curing conditions. In Proceedings of 13th International Congress on the Chemistry of Cement, Madrid, Spain, 3-8 July 2011.

8. Liu, Z.; El-Tawil, S.; Hansen, W.; Wang, F. Effect of slag cement on the properties of ultra-high performance concrete. Constr. Build. Mater. 2018, 190, 830-837. [CrossRef]

9. Castellano, C.C.; Bonavetti, V.L.; Donza, H.A.; Irassar, E.F. The effect of $w / b$ and temperature on the hydration and strength of blastfurnace slag cements. Constr. Build. Mater. 2016, 111, 679-688. [CrossRef]

10. Kim, Y.; Hanif, A.; Usman, M.; Munir, M.J.; Kazmi, S.M.S.; Kim, S. Slag waste incorporation in high early strength concrete as cement replacement: Environmental impact and influence on hydration \& durability attributes. J. Clean. Prod. 2018, 172, 3056-3065. [CrossRef]

11. Bougara, A.; Lynsdale, C.; Milestone, N.B. The influence of slag properties, mix parameters and curing temperature on hydration and strength development of slag/cement blends. Constr. Build. Mater. 2018, 187, 339-347. [CrossRef]

12. Kandiri, A.; Mohammadi Golafshani, E.; Behnood, A. Estimation of the compressive strength of concretes containing ground granulated blast furnace slag using hybridized multi-objective ANN and salp swarm algorithm. Constr. Build. Mater. 2020, 248, 118676. [CrossRef]

13. Wan, S.; Zhou, X.; Zhou, M.; Han, Y.; Chen, Y.; Geng, J.; Wang, T.; Xu, S.; Qiu, Z.; Hou, H. Hydration characteristics and modeling of ternary system of municipal solid wastes incineration fly ash-blast furnace slag-cement. Constr. Build. Mater. 2018, 180, 154-166. [CrossRef]

14. Tan, Z.; De Schutter, G.; Ye, G.; Gao, Y.; Machiels, L. Influence of particle size on the early hydration of slag particle activated by $\mathrm{Ca}(\mathrm{OH}) 2$ solution. Constr. Build. Mater. 2014, 52, 488-493. [CrossRef] 
15. Xie, F.; Liu, Z.; Zhang, D.; Wang, J.; Huang, T.; Wang, D. Reaction kinetics and kinetics models of alkali activated phosphorus slag. Constr. Build. Mater. 2020, 237, 117728. [CrossRef]

16. Fernández, Á.; Lothenbach, B.; Alonso, M.C.; García Calvo, J.L. Thermodynamic modelling of short and long term hydration of ternary binders. Influence of Portland cement composition and blast furnace slag content. Constr. Build. Mater. 2018, 166, 510-521. [CrossRef]

17. Schöler, A.; Lothenbach, B.; Winnefeld, F.; Zajac, M. Hydration of quaternary Portland cement blends containing blast-furnace slag, siliceous fly ash and limestone powder. Cem. Concr. Compos. 2015, 55, 374-382. [CrossRef]

18. Han, F.; Zhang, Z.; Wang, D.; Yan, P. Hydration kinetics of composite binder containing slag at different temperatures. J. Therm. Anal. Calorim. 2015, 121, 815-827. [CrossRef]

19. Gruyaert, E.; Robeyst, N.; De Belie, N. Study of the hydration of Portland cement blended with blast-furnace slag by calorimetry and thermogravimetry. J. Therm. Anal. Calorim. 2010, 102, 941-951. [CrossRef]

20. Lee, H.S.; Wang, X.Y.; Zhang, L.N.; Koh, K.T. Analysis of the Optimum Usage of Slag for the Compressive Strength of Concrete. Materials 2015, 8, 1213-1229. [CrossRef] [PubMed]

21. Lee, H.-S.; Wang, X.-Y. Hydration Model and Evaluation of the Properties of Calcined Hwangtoh Binary Blends. Int. J. Concr. Struct. Mater. 2021, 15, 11. [CrossRef]

22. Maekawa, K.; Ishida, T.; Kishi, T. Multi-Scale Modeling of Structural Concrete; Taylor \& Francis: London, UK; New York, NY, USA, 2009.

23. Thomas, M. Supplementary Cementing Materials in Concrete; CRC Press: Boca Raton, FL, USA, 2013.

24. Wang, X.-Y.; Luan, Y. Modeling of Hydration, Strength Development, and Optimum Combinations of Cement-Slag-Limestone Ternary Concrete. Int. J. Concr. Struct. Mater. 2018, 12, 12. [CrossRef]

25. Ishida, T.; Luan, Y.; Sagawa, T.; Nawa, T. Modeling of early age behavior of blast furnace slag concrete based on micro-physical properties. Cem. Concr. Res. 2011, 41, 1357-1367. [CrossRef]

26. Luan, Y.; Ishida, T.; Nawa, T.; Sagawa, T. Enhanced Model and Simulation of Hydration Process of Blast Furnace Slag in Blended Cement. J. Adv. Concr. Technol. 2012, 10, 1-13. [CrossRef]

27. Park, S.; Abate, S.Y.; Kim, H.-K. Hydration kinetics modeling of sodium silicate-activated slag: A comparative study. Constr. Build. Mater. 2020, 242, 118144. [CrossRef]

28. Cho, H.-K. A Study on the Prediction Model of Concrete Carbonation Using Cement Hydration Model Incorporating Ground Granulated Blast Furnace Slag. Ph.D. Thesis, Hanyang University, Seoul, Korea, 2015.

29. Feng, X.; Garboczi, E.J.; Bentz, D.P.; Stutzman, P.E.; Mason, T.O. Estimation of the degree of hydration of blended cement pastes by a scanning electron microscope point-counting procedure. Cem. Concr. Res. 2004, 34, 1787-1793. [CrossRef]

30. Kocaba, V.; Gallucci, E.; Scrivener, K.L. Methods for determination of degree of reaction of slag in blended cement pastes. Cem. Concr. Res. 2012, 42, 511-525. [CrossRef]

31. Yio, M.H.N.; Phelan, J.C.; Wong, H.S.; Buenfeld, N.R. Determining the slag fraction, water/binder ratio and degree of hydration in hardened cement pastes. Cem. Concr. Res. 2014, 56, 171-181. [CrossRef]

32. Lee, H.-S.; Lim, S.-M.; Wang, X.-Y. Optimal Mixture Design of Low- $\mathrm{CO}_{2}$ High-Volume Slag Concrete Considering Climate Change and $\mathrm{CO}_{2}$ Uptake. Int. J. Concr. Struct. Mater. 2019, 13, 56. [CrossRef] 